\title{
Fe-doped 8YSZ at different composition for solid electrolyte in solid oxide fuel cell
}

\author{
B. Johar ${ }^{1, *}$, and N.A. Zaili ${ }^{1}$ \\ ${ }^{1}$ School of Materials Engineering, Universiti Malaysia Perlis, 02600 Kangar, Perlis, Malaysia
}

\begin{abstract}
Pure $8 \mathrm{~mol} \%$ yttria stabilized zirconia (YSZ) and Fe-doped (1 $\mathrm{mol} \%, 2 \mathrm{~mol} \%$ and $3 \mathrm{~mol} \%$ ) YSZ electrolyte were prepared and sintered at $1550^{\circ} \mathrm{C}$. Transition metal oxide is added into YSZ as sintering aided has a function to reduce the sintering temperature. The microstructure, crystal structure and ionic conductivity of pure YSZ and Fe-doped YSZ at different composition were investigated. The amount of cubic phase decreased as the amount of Fe increased. Fe-doped 8YSZ had higher conductivity than pure $8 \mathrm{YSZ}$. The ionic conductivity of $3 \mathrm{FeYSZ}$ is $9.35 \times 10^{-8} \mathrm{~S} / \mathrm{cm}$ higher than $1 \mathrm{FeYSZ}$ which is $4.72 \times 10^{-9} \mathrm{~S} / \mathrm{cm}$ when operated at $300^{\circ} \mathrm{C}$.
\end{abstract}

\section{Introduction}

Yttria stabilized zirconia (YSZ) is regularly utilized as electrolyte for SOFC because of its pure and high ionic conductivity at elevated temperature, chemical stability, low thermal expansion coefficient and good stability in both oxidizing and reducing gases [1,6]. YSZ has high ionic conductivity and chemical stability in oxidizing atmosphere. Zirconia $\left(\mathrm{ZrO}_{2}\right)$ is a thermal insulator with high thermodynamic and chemical stability. On 2013, Figueiredo and his team reported doping Zirconia with Yttria replaces $\mathrm{Zr}^{4+}$ with $\mathrm{Y}^{3+}$ by addition of oxygen vacancies and ionic conductivity. $8 \mathrm{~mol} \%$ of Yttria stabilized zirconia (8YSZ) is the most preferred electrolyte material because it has excellent stability and pure ionic conductivity at typical operating temperature [21].

Transition metal oxides have proven as a good sintering promoter especially for the densification of SOFC electrolytes [1]. From the previous research by Satardekar et al. [2] and Zhang et al. [23], Fe is has been widely used because of effective dopant for YSZ electrolyte to enhance the performance of YSZ electrolyte.

Zhang et al. [23] studied that the maximum relative density which is almost $\sim 98 \%$ of transition metal oxide of pure and doped Si-containing 8YSZ can be maintained when sintered at $1550^{\circ} \mathrm{C}$. However, the lack of studied has been found for the different composition of $\mathrm{Fe}$ doped $8 \mathrm{YSZ}$ for sintering temperature at $1550^{\circ} \mathrm{C}$. Therefore, in this research pure $8 \mathrm{YSZ}$ and different amounts of $\mathrm{Fe}(1 \mathrm{~mol} \%$ of $\mathrm{Fe}, 2 \mathrm{~mol} \%$ of $\mathrm{Fe}$ and $3 \mathrm{~mol} \%$ ) was doped in $8 \mathrm{YSZ}$ ceramics.

\footnotetext{
* Corresponding author: banjuraizah@unimap.edu.my
} 


\section{Experimental}

Iron $(\mathrm{Fe})$-doped YSZ electrolyte powders were prepared using8 mol\% yttria stabilized zirconia (8YSZ) powder and pure $\mathrm{Fe}_{2} \mathrm{O}_{3}$ powders. They were weighted according to the mole as $1 \mathrm{~mol} \%$ of $\mathrm{Fe}$ (1FeYSZ), $2 \mathrm{~mol} \%$ of $\mathrm{Fe}$ (2FeYSZ) and $3 \mathrm{~mol} \%$ of $\mathrm{Fe}$ (3FeYSZ). The mixture of $8 \mathrm{YSZ}$ with $\mathrm{Fe}_{2} \mathrm{O}_{3}$ powder were ground by mortar and pestle with ethanol for 30 minutes until homogeneous mixture was obtained. The powders were then calcined at $1000^{\circ} \mathrm{C}$ and hold for $1 \mathrm{~h}$ for $10^{\circ} \mathrm{C} / \mathrm{min}$. The calcined powders were ground using mortar and pestle prior compacted in a cylindrical die of $12 \mathrm{~mm}$ diameter at 6 tonnes for 2 minutes. The compacted pellets were then sintered at $1550^{\circ} \mathrm{C}$ for 2 hours. .XRD was carried out using scan range $5-90^{\circ} \mathrm{C}$ and scan axis with a continuous $1{ }^{\circ} \mathrm{C} / \mathrm{min}$, step scan of $7 \mathrm{~s}$ and step size of 2 thetas. XRD patterns of the sintered samples were obtained using a model SHIMADZU XRD 6000 X-ray diffractometer with $\mathrm{Cu} \mathrm{K} \alpha$ radiation of $50 \mathrm{~mA}$ and $40 \mathrm{kV}$. Morphology and microstructure of sample was investigate using SEM measurements was model JEOL JSM-6460LA. The sintered samples doped 8 YSZ were coated with gold by using sputter coating before tested by the SEM to eliminate the charging effect. For the conductivity measurement, the impedance spectroscopy was used to determine the conductivity of the samples. The impedance spectroscopy measurement was carried out by impedance analyzer model Agilent 4294A. The ionic conductivity of the sintered pure and doped 8YSZ samples (coated and uncoated) were tested at high temperature which is $100^{\circ} \mathrm{C}, 200^{\circ} \mathrm{C}$ and $300^{\circ} \mathrm{C}$. The conductivity value of coated and uncoated samples was measured at increasing temperature. The sample is fixed in the spring loaded sample holder prior dielectric properties measurement. The data was collected during heating. The measurement was conducted in air at room temperature and high temperature in a frequency range of $5000000 \mathrm{~Hz}-4 \mathrm{~Hz}$.

\section{Results and discussion}

\subsection{Differential thermal analysis/ thermogravimetric analysis (DTA/TGA)}

The ideal temperature and phase transformations of the calcined powder were studied by using DTA/TGA. The weight is monitored as a function of temperature. DTA was used to observe all the decomposition reaction and determine the crystallization behavior. Figure 1 showed exothermic peaks corresponding to various stages of weight loss were observed in DTA plot. The exothermic was occurred and the maximum rate of mass-change was $3 \mathrm{FeYSZ}$ which is at temperature around $1183^{\circ} \mathrm{C}$ while the lowest was pure $\mathrm{YSZ}$ which is at temperature $1238^{\circ} \mathrm{C}$. The crystallization temperatures for $1 \mathrm{FeYSZ}$ and $2 \mathrm{FeYSZ}$ were $1186^{\circ} \mathrm{C}$ and $1223^{\circ} \mathrm{C}$ respectively. The crystallization temperature decreased as the composition increased due to the crystallization of certain phases.

TGA was used to detect loss in mass and quantity the change in physical or chemical properties of the materials as a function of temperature or time. Figure 2 showed weight gains occurred for all calcined powder (pure YSZ, 1FeYSZ, 2FeYSZ and 3FeYSZ) as the Tg curve increased. All samples showed almost similar trend. Fe-doped 8YSZ increase slightly uniformly up to temperature $1337^{\circ} \mathrm{C}$. As the composition of Fe-doped $8 \mathrm{YSZ}$ increase which is $1 \mathrm{FeYSZ}, 2 \mathrm{FeYSZ}$ and $3 \mathrm{FeYSZ}$, the weight gain decrease as $0.22 \mathrm{mg}$, $0.21 \mathrm{mg}$ and $0.20 \mathrm{mg}$ respectively. Weight gains occurred due to the oxidation of the samples. 


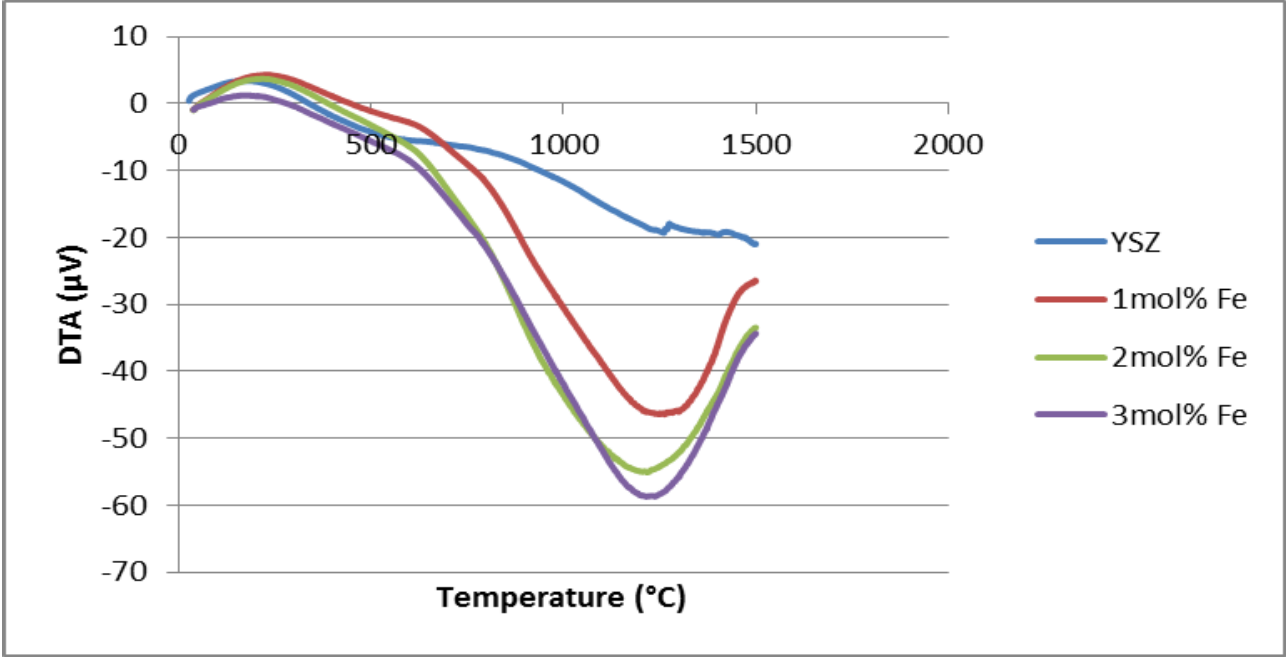

Fig. 1. The DTA graph for pure YSZ and Fe doped 8 YSZ (1FeYSZ, 2FeYSZ and 3FeYSZ).

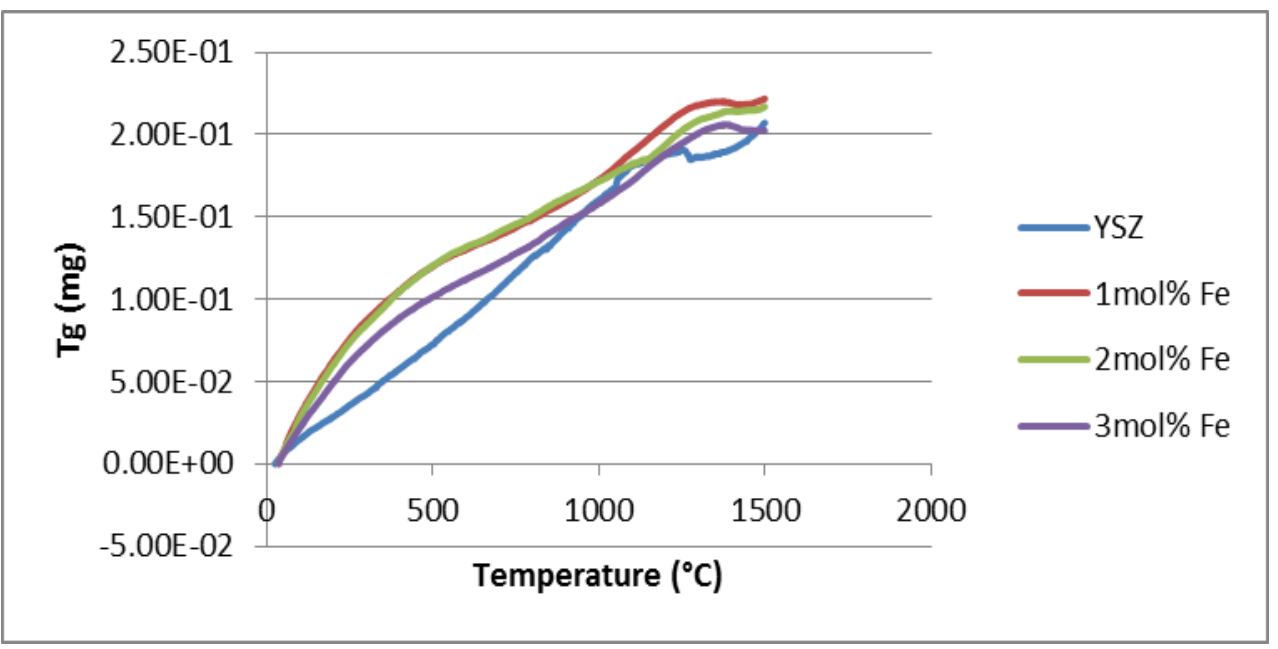

Fig. 2. The DTA graph for pure YSZ and Fe doped $8 Y S Z$ (1FeYSZ, 2FeYSZ and 3FeYSZ).

\subsection{Phase composition}

Figure 3 shows XRD pattern of Fe-doped $8 \mathrm{YSZ}$ electrolyte sintered at $1550^{\circ} \mathrm{C}$ at different composition. There are mixed phases corresponds to tetragonal and monoclinic phase in pure 8YSZ sample. While all tetragonal, cubic and monoclinic are present in Fe doped $8 Y S Z$ samples. No characteristic peak belong to $\mathrm{Fe}_{2} \mathrm{O}_{3}$ has been detected. The predominant phase for undoped 8 YSZ samples is tetragonal phase. Rietveld quantitative phase analysis demonstrates phase composition of sample as shown in Figure 4. When the concentration of Fe increased, the proportion of tetragonal phase decreased. The addition of Fe into 8YSZ up to $1 \mathrm{~mol} \%$ has resulted in crystallization of cubic phase, however the amount of cubic phase tend to decrease with increasing amount of Fe. The decomposition of cubic phases was expected related to crystallization of monoclinic phase. The higher the amount of Fe added into $8 \mathrm{YSZ}$ ceramics has distorted the crystal lattice and caused the formation of monoclinic phase. Unlike pure YSZ, high doping of Fe has retarded the formation of 
tetragonal or cubic phase. This is because certain concentration of dopant has scattered in the grain boundaries and resisted the formation of tetragonal phase. The dopant might also substitution or interstitial in the lattice and consequently cause distortion of lattice. The contraction or expansion of the YSZ lattice parameter can be observed by looking at changes of crystal volume as demonstrated in Table 1. It can be observed that, with the addition of $\mathrm{Fe}$, the crystal volume of tetragonal phase tend to decrease. This is because $\mathrm{Fe}^{3+}$ ions have ionic radius which is $0.055 \mathrm{~nm}$ smaller than $\mathrm{Zr}^{4+}$ ions which is $0.084 \mathrm{~nm}$, substitution of $\mathrm{Zr}^{4+}$ ions with smaller $\mathrm{Fe}^{3+}$ ions induce the variation in lattice parameter, thus decrease the volume of the unit cell [22]. The decreasing of crystal volume for both monoclinic and tetragonal phase proved that $\mathrm{Fe}$ has substitute zirconium or yttrium atom in the fluorite structure, while small expansion in cubic structure might due to the interstitial of $\mathrm{Fe}$ atom inside the crystal lattice. The results were in contrast with what Nakajima and his team found where they reported that the crystal structure of cubic phase was not changed by Fe doping [6].

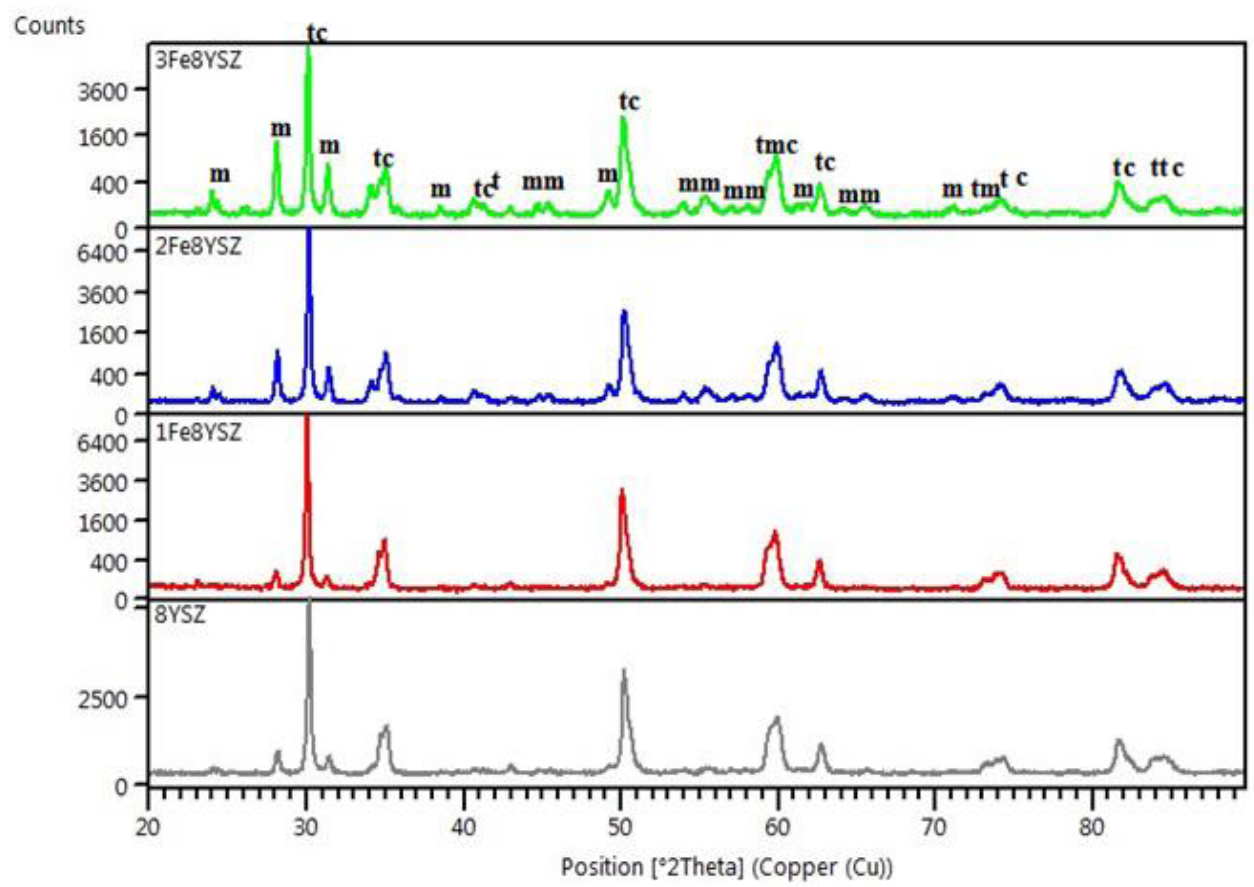

Fig. 3. XRD profile for the sintered samples of pure YSZ, Fe (1,2,3mol\%) doped $8 \mathrm{YSZ}$ samples. (t:tetragonal \#icsd no 98-002-0789, m:monoclinic \#icsd no98-07-1860, c:cubic \#iscd no 98-0050481). 


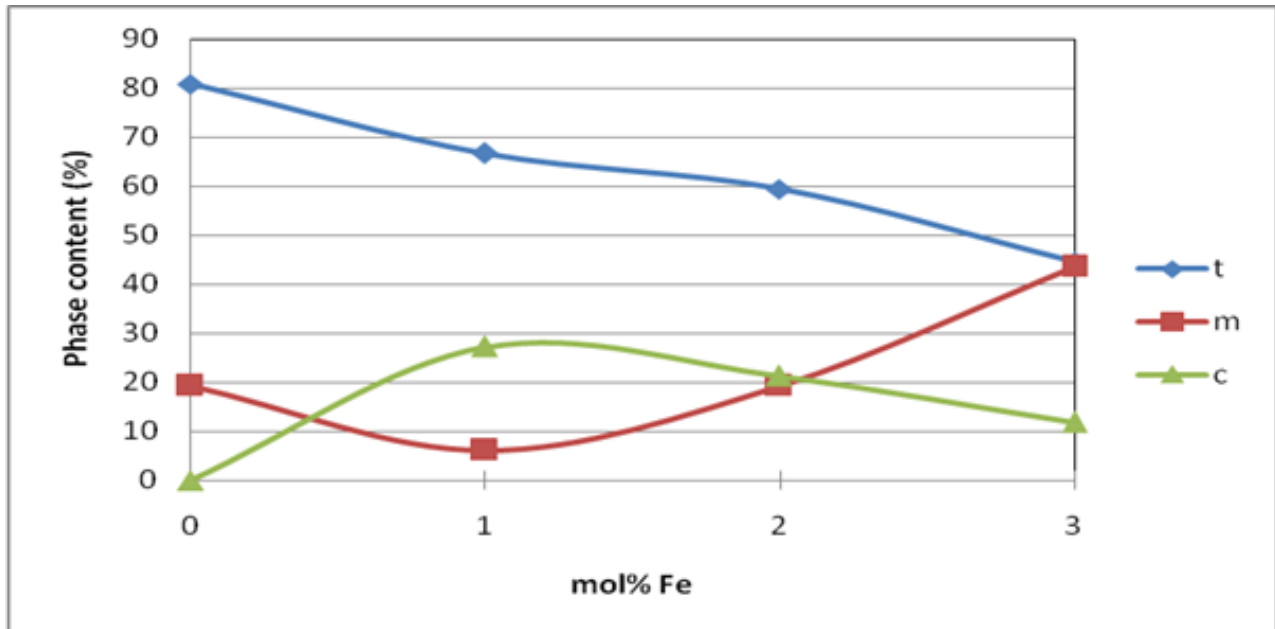

Fig. 4. Phase composition of sintered samples with doped with different amount of Fe.

Table 1. Crystal volume of phases that are present in undoped and Fe doped 8YSZ samples.

\begin{tabular}{|c|c|c|c|}
\hline \multirow{2}{*}{ mol\% Fe } & \multicolumn{3}{|c|}{ Crystal volume $\left(\mathbf{A}^{\mathbf{0 3}}\right)$} \\
\cline { 2 - 4 } & tetragonal & monoclinic & cubic \\
\hline 0 & 67.61 & 142.05 & 0.00 \\
\hline 1 & 67.32 & 142.00 & 135.10 \\
\hline 2 & 67.42 & 141.24 & 135.20 \\
\hline 3 & 67.40 & 141.20 & 135.28 \\
\hline
\end{tabular}

\subsection{Phase composition SEM morphology observation}

The SEM morphologies of pure $8 \mathrm{YSZ}, 1 \mathrm{FeYSZ}, 2 \mathrm{FeYSZ}$ and $3 \mathrm{FeYSZ}$ sintered at $1550^{\circ} \mathrm{C}$ were shown in Fig. 4 (a)-(d) at magnification X10000 respectively. The pure YSZ showed the spherical shaped. The SEM micrograph indicated that dopant gave great effects on the microstructure of the $8 \mathrm{YSZ}$. Addition of $\mathrm{Fe}$ in $8 \mathrm{YSZ}$ promoted the grain growth and densification. This also has resulted in non-homogeneous distribution of grain sizes. The grain size increased as the Fe concentration [2]. The figure showed that the grain size increased until $2 \mathrm{FeYSZ}$ and decreased when doped with $3 \mathrm{FeYSZ}$ concentration. It shows grain boundary with minimum grain size around $1 \mu \mathrm{m}$ and maximum grain size around $8 \mu \mathrm{m}$.

\subsection{Ionic conductivities}

Impedance diagrams of samples sintered at $1550^{\circ} \mathrm{C}$ is shown in Figure 5 for pure YSZ, $1 \mathrm{FeYSZ}, 2 \mathrm{FeYSZ}$ and $3 \mathrm{FeYSZ}$ operated at $300^{\circ} \mathrm{C}$. The trend of conductivity as a function of studied parameter showed one semicircle for the impedance plots measured at $300^{\circ} \mathrm{C}$. Decrement in grain resistivity illustrated that the sintered samples had higher conductivity [24]. $3 \mathrm{FeYSZ}$ has smaller grain resistivity compare to $1 \mathrm{FeYSZ}$. Therefore, 3FeYSZ has higher conductivity than those pure and doped sintered samples. This might be due to the $\mathrm{Fe}$ dopant may improve electrolyte-electrodes interfaces of SOFCs causing the power 
output to increase [1]. The ionic conductivity of $3 \mathrm{FeYSZ}$ is $9.35 \times 10^{-8} \mathrm{~S} / \mathrm{cm}$ higher than $1 \mathrm{FeYSZ}$ which is $4.72 \times 10^{-9} \mathrm{~S} / \mathrm{cm}$ when operated at $300^{\circ} \mathrm{C}$.

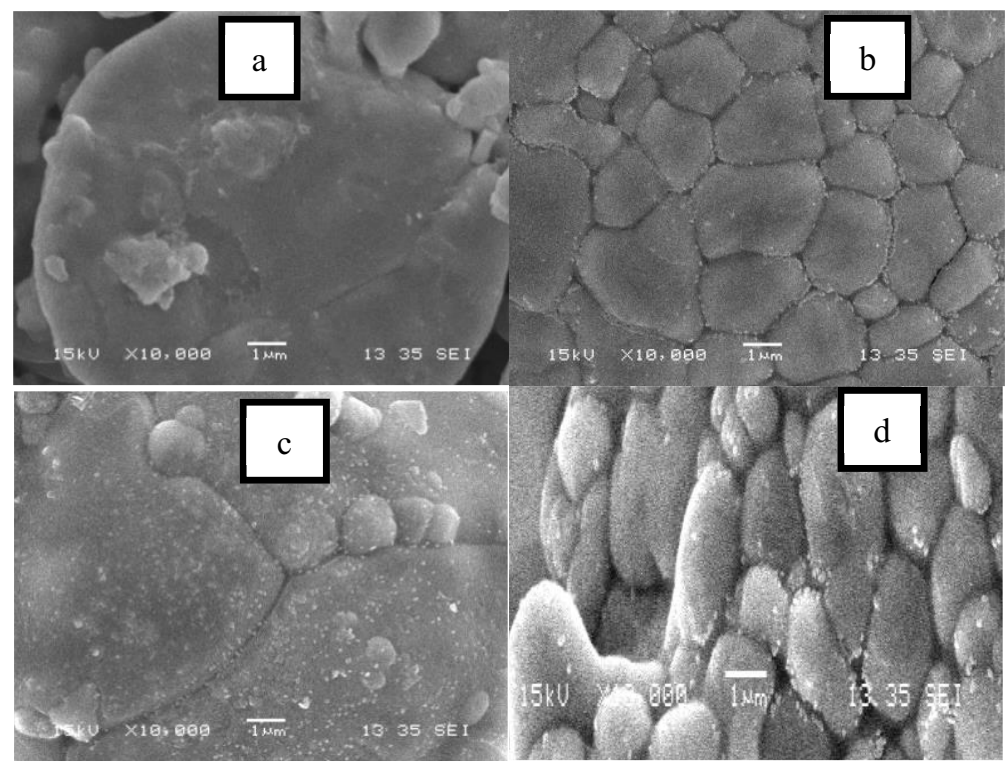

Fig. 4. SEM micrograph of pellets prepared from powder with different mol\% of Fe: (a) pure YSZ, (b) $1 \mathrm{FeYSZ}$, (c) $2 \mathrm{FeYSZ}$ and (d) $3 \mathrm{FeYSZ}$.

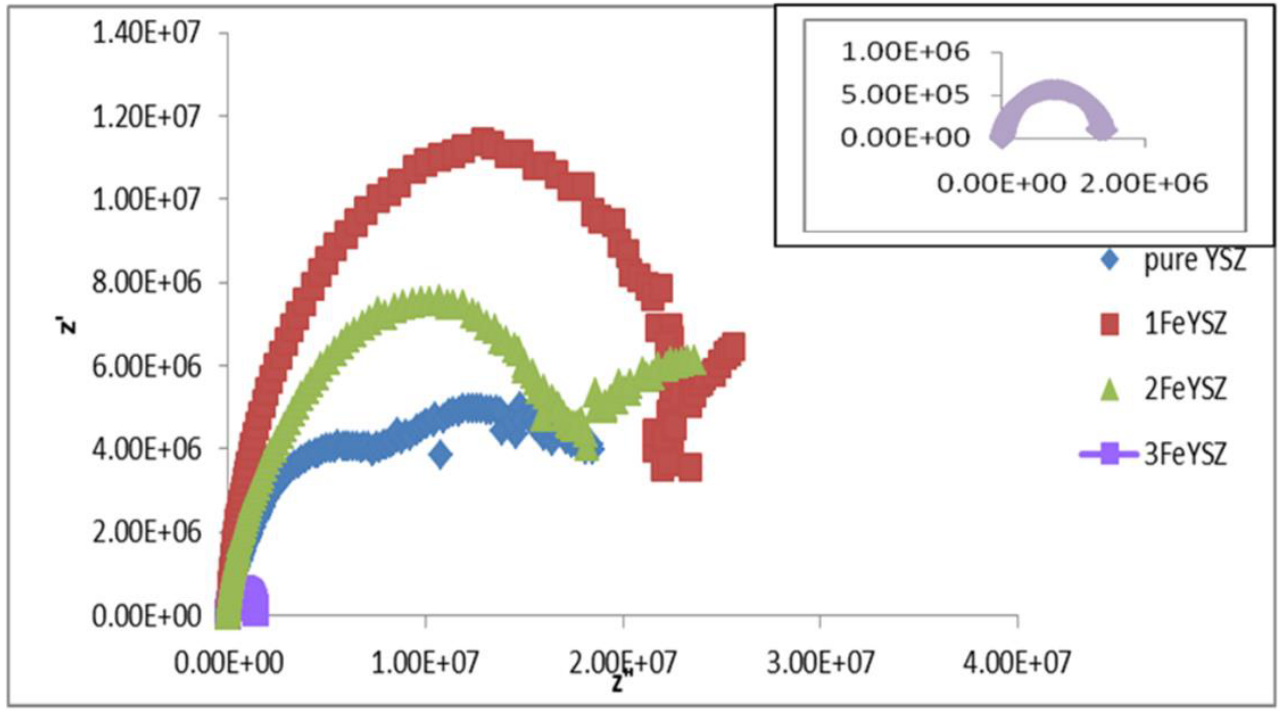

Fig. 5.Impedance spectra of sintered pure YSZ, $1 \mathrm{FeYSZ}, 2 \mathrm{FeYSZ}$ and $3 \mathrm{FeYSZ}$ operated at $300^{\circ} \mathrm{C}$.

\section{Conclusion}

Fe-doped 8YSZ was found to be a suitable electrolyte material in solid oxide fuel cell. The crystallization temperature decreased as the composition increased. As the addition of $\mathrm{Fe}$ increased, the crystal volume of tetragonal phase tend to decrease because $\mathrm{Fe}^{3+}$ ions have ionic radius which is $0.055 \mathrm{~nm}$ smaller than $\mathrm{Zr}^{4+}$ ions which is $0.084 \mathrm{~nm}$, substitution of 
$\mathrm{Zr}^{4+}$ ions with smaller $\mathrm{Fe}^{3+}$ ions induce the variation in lattice parameter, thus decrease the volume of the unit cellThe conductivity of Fe-doped $8 \mathrm{YSZ}$ was found to be slightly higher than pure $8 \mathrm{YSZ}$. 3FeYSZ has lower grain resistivity and thus has higher conductivity.

\section{References}

1. H. Gao, J. Liu, H. Chen, S. Li, T. He, Zhang, J. Solid State Ionics, 179, 1620 (2008)

2. P. Satardekar, D. Montinaro, V.M. Sglavo, Ceramics International, 41, 9806 (2015)

3. T. Dey, A.D. Sharma, A. Dutta, R.N. Basu, J. Alloys Compd., 604, 151 (2014)

4. In Jin Shon, In Kyoon Jeong, Jeong-Hwan Park, Byung-Ryang Kim, Lee, K.T., Ceramics International, 35, 363 (2009)

5. O. Bohnke, V. Gunes, K.V. Krachyk, A.G. Belous, O.Z.Y Anchevskii, V. Yunov, O.I.V. Yunov, Solid State Ionics, 262, 517 (2014)

6. H. Nakajima, K. Itoh, H. Kaneko, Y. Tamaura, J. Phys. Chem. Solids, 68, 1946 (2007)

7. GurpreetKaur, S. Basu, J. Power Sources, 241, 783(2013)

8. S. Bang, University of California, Irvine (2008)

9. M.L. Perry, T.F. Fuller, J. Electrochem. Soc., 149, 59 (2002)

10. S.P.S Badwal, K. Foger, In. Ceram. Int., 22, 257 (1996)

11. Chih Wei Kuoa, Y. H.S., I. Ming Hungb, Shaw Bing Wenc, M.C. Huey ErLeed., J. Alloys Compd., 8 (2008)

12. Kaiser, A.J. Feighery, D.P. Fagg, J.T. Irvine, Ionics 4, 215 (1998)

13. G.S. Lewis, A. Atkinson, B.C.H. Steele, J. Mater. Sci. Lett., 1155 (2001)

14. J. Schefold, A. Brisse, M. Zahid, J. Electrochem. Soc., 156, 897 (2009)

15. J.H. Kim, G.M. Choi., Solid State Ionics, 130, 157 (2000)

16. S. Linderoth, N. Bonanos, K.V. Jensen, J.B.B. Sorensen, J. Am. Ceram. Soc., 84, $2652(2001)$

17. H. Yakonawa, N. Sakai, T. Horita, K. Yamaji, M.E. Brito, MRS Bulletin, 30, 591 (2005)

18. J.W. Fergus, J. Power Sources, 30 (2006)

19. E.C. SubbaRao, H.S. Maiti, Solid State Ionics, 11, 317 (1984)

20. F. Gou, P. Xiao, Ceram. Soc., 32, 4157 (2012)

21. Q. Dong, Z.H. Du, T.S. Zhang, J. Lu, X.C. Song, J. Ma, Int. J. Hydrog. Energy, 34, 7903 (2009)

22. F.M.L. Figueiredo, F.M.B. Marques, WIREs Energy Environ., 2, 52 (2013)

23. T.S. Zhang, Z.H. Du, S. Li, L.B. Kong, X.C. Song, J. Lu, Solid State Ionics, 180, $1311(2009)$

24. B. Meng, Z.Y. Miao, M. Kong, X.X. Liu, Q.Q. Yang, Solid State Ionics, 258, 61 (2014) 